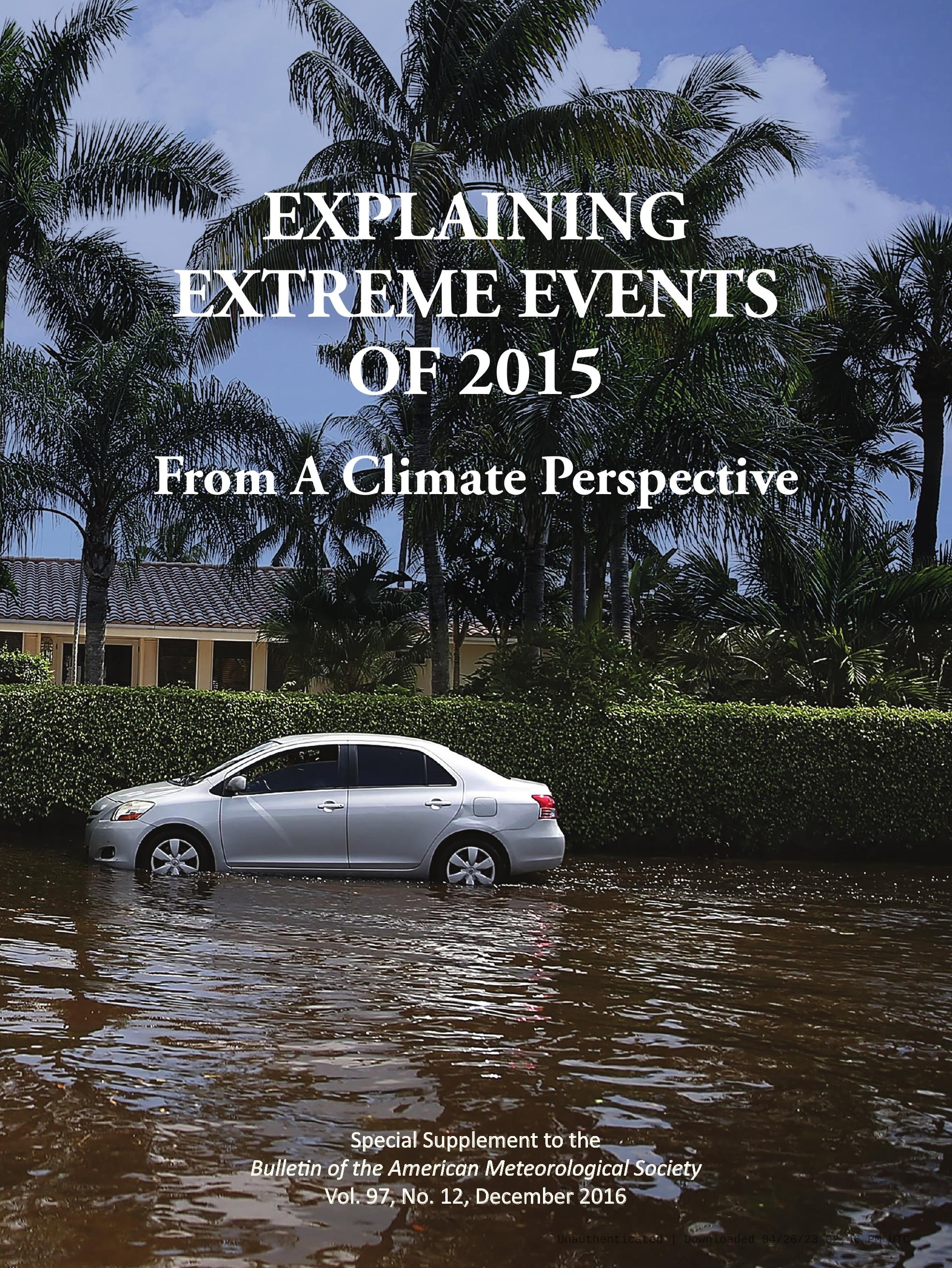




\section{EXPLAINING EXTREME \\ EVENTS OF 20I5 FROM A \\ CLIMATE PERSPECTIVE}

\section{Editors}

Stephanie C. Herring, Andrew Hoell, Martin P. Hoerling, James P. Kossin,

Carl J. Schreck III, and Peter A. Stott

Special Supplement to the

Bulletin of the American Meteorological Society

Vol. 97, No. 12, December 2016

American Meteorological Society 


\section{CORRESPONDING EDITOR:}

Stephanie C. Herring, PhD

NOAA National Centers for Environmental Information

325 Broadway, E/CC23, Rm IB-I3I

Boulder, CO, 80305-3328

E-mail: stephanie.herring@noaa.gov

\section{Cover CRedit:}

CPhoto by Joe Raedle/Getty Images-A vehicle drives through flooded streets caused by a combination of the lunar orbit which caused seasonal high tides and what many believe is the rising sea levels due to climate change on September 30, 20I5, in Fort Lauderdale, Florida. South Florida is projected to continue to feel the effects of climate change, and many of the cities have begun programs such as installing pumps or building up sea walls to try and combat the rising oceans.

\section{HOW TO CITETHIS DOCUMENT}

Citing the complete report:

Herring, S. C., A. Hoell, M. P. Hoerling, J. P. Kossin, C. J. Schreck III, and P.A. Stott, Eds., 20I6: Explaining Extreme Events of 2015 from a Climate Perspective. Bull.Amer. Meteor. Soc., 97 (I 2), SI-SI 45.

Citing a section (example):

Partain, J. L., and Coauthors, 2016: An assessment of the role of anthropogenic climate change in the Alaska fire season of 2015 [in "Explaining Extremes of 2015 from a Climate Perspective"]. Bull. Amer. Meteor. Soc., 97 (I2), SI4-SI8, doi:I0.II75/BAMS-D-16-0149.

\section{EDITORIAL AND PRODUCTION TEAM}

Riddle, Deborah B., Lead Graphics Production, NOAA/NESDIS National Centers for Environmental Information,

Asheville, NC

Veasey, Sara W., Visual Communications Team Lead, NOAA/ NESDIS National Centers for Environmental Information, Asheville, NC

Love-Brotak, S. Elizabeth, Graphics Support, NOAA/NESDIS National Centers for Environmental Information,

Asheville, NC

Fulford, Jennifer, Editorial Support, Telesolv Consulting LLC, NOAA/NESDIS National Centers for Environmental Information, Asheville, NC

Griffin, Jessicca, Graphics Support, Cooperative Institute for Climate and Satellites-NC, North Carolina State University, Asheville, NC
Maycock, Tom, Editorial Support, Cooperative Institute for Climate and Satellites-NC, North Carolina State University, Asheville, NC

Misch, Deborah J., Graphics Support, Telesolv Consulting LLC, NOAA/NESDIS National Centers for Environmental Information, Asheville, NC

Osborne, Susan, Editorial Support, Telesolv Consulting LLC, NOAA/NESDIS National Centers for Environmental Information, Asheville, NC

Sprain, Mara, Editorial Support, LAC Group, NOAA/NESDIS National Centers for Environmental Information, Asheville, NC

Young, Teresa, Graphics Support, STG, Inc., NOAA/NESDIS National Centers for Environmental Information, Asheville, NC 


\section{TABLE OF CONTENTS}

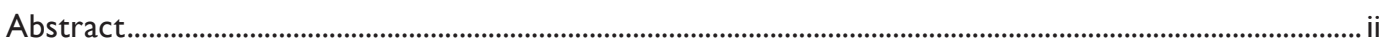

I. Introduction to Explaining Extreme Events of 2015 from a Climate Perspective.................................

2. Multimodel Assessment of Anthropogenic Influence on Record Global and Regional Warmth

During 2015 .......................................................................................................................................

3. What History Tells Us About 2015 U.S. Daily Rainfall Extremes ..........................................................

4. An Assessment of the Role of Anthropogenic Climate Change in the Alaska Fire Season

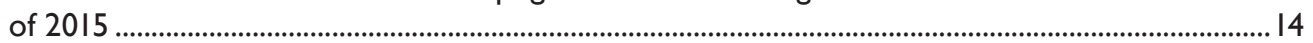

5. The 2014/15 Snowpack Drought in Washington State and its Climate Forcing ................................19

6. In Tide's Way: Southeast Florida's September 2015 Sunny-day Flood ................................................. 25

7. Extreme Eastern U.S. Winter of 2015 Not Symptomatic of Climate Change .....................................

8. The Role of Arctic Sea Ice and Sea Surface Temperatures on the Cold 2015 February

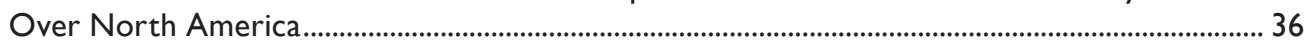

9. The 2015 Extreme Drought in Western Canada ................................................................................ 42

10. Human Contribution to the Record Sunshine of Winter 2014/15 in the United Kingdom .............47

II. The Role of Anthropogenic Warming in 2015 Central European Heat Waves ...................................5I

12. The 2015 European Heat Wave ..................................................................................................................

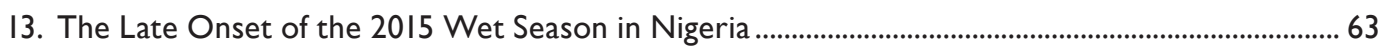

14. Human Influences on Heat-Related Health Indicators During the 2015 Egyptian Heat Wave .................................................................................................................................. 70

15. Assessing the Contributions of Local and East Pacific Warming to the 2015

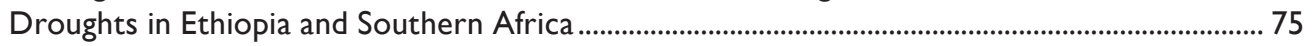

16. The Deadly Combination of Heat and Humidity in India and Pakistan in Summer 2015..................8I

17. The Heavy Precipitation Event of December 2015 in Chennai, India................................................... 87

18. Attribution of Extreme Rainfall in Southeast China During May 2015 ............................................. 92

19. Record-Breaking Heat in Northwest China in July 2015: Analysis of the Severity and Underlying Causes ......................................................................................................................... 97

20. Human Influence on the 2015 Extreme High Temperature Events in Western China................... 102

21. A Persistent Japanese Heat Wave in Early August 2015: Roles of Natural Variability and

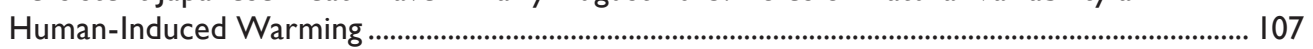

22. Climate Change and El Niño Increase Likelihood of Indonesian Heat and Drought........................ 113

23. Southern Australia's Warmest October on Record: The Role of ENSO and Climate Change....................................................................................................................................... 118

24. What Caused the Record-Breaking Heat Across Australia in October 2015? .............................. 122

25. The Roles of Climate Change and El Niño in the Record Low Rainfall in October 2015 in Tasmania, Australia.

26. Influences of Natural Variability and Anthropogenic Forcing on the Extreme 2015 Accumulated Cyclone Energy in the Western North Pacific

27. Record Low Northern Hemisphere Sea Ice Extent in March 2015 ............................................... 136

28. Summary and Broader Context.....................................................................................................141 
This fifth edition of explaining extreme events of the previous year (2015) from a climate perspective continues to provide evidence that climate change is altering some extreme event risk. Without exception, all the heat-related events studied in this year's report were found to have been made more intense or likely due to human-induced climate change, and this was discernible even for those events strongly influenced by the $2015 \mathrm{El}$ Niño. Furthermore, many papers in this year's report demonstrate that attribution science is capable of separating the effects of natural drivers including the strong 2015 El Niño from the influences of long-term human-induced climate change.

Other event types investigated include cold winters, tropical cyclone activity, extreme sunshine in the United Kingdom, tidal flooding, precipitation, drought, reduced snowpack in the U.S. mountain west, arctic sea ice extent, and wildfires in Alaska. Two studies investigated extreme cold waves and monthly-mean cold conditions over eastern North America during 2015, and find these not to have been symptomatic of human-induced climate change. Instead, they find the cold conditions were caused primarily by internally generated natural variability. One of these studies shows winters are becoming warmer, less variable, with no increase in daily temperature extremes over the eastern United States. Tropical cyclone activity was extreme in 2015 in the western North Pacific (WNP) as measured by accumulated cyclone energy (ACE). In this report, a study finds that human-caused climate change largely increased the odds of this extreme cyclone activity season. The 2015 Alaska fire season burned the second largest number of acres since records began in 1940. Investigators find that human-induced climate change has increased the likelihood of a fire season of this severity.

Confidence in results and ability to quickly do an attribution analysis depend on the "three pillars" of event attribution: the quality of the observational record, the ability of models to simulate the event, and our understanding of the physical processes that drive the event and how they are being impacted by climate change. A result that does not find a role for climate change may be because one or more of these three elements is insufficient to draw a clear conclusion. As these pillars are strengthened for different event types, confidence in the presence and absence of a climate change influence will increase.

This year researchers also link how changes in extreme event risk impact human health and discomfort during heat waves, specifically by looking at the role of climate change on the wet bulb globe temperature during a deadly heat wave in Egypt. This report reflects a growing interest within the attribution community to connect attribution science to societal impacts to inform risk management through "impact attribution." Many will watch with great interest as this area of research evolves in the coming years. 


\title{
I8. ATTRIBUTION OF EXTREME RAINFALL IN SOUTHEAST CHINA DURING MAY 2015
}

\author{
Claire Burke, Peter Stott, Ying Sun, and Andrew Ciavarella
}

Anthropogenic climate change increased the probability that a short-duration, intense rainfall event would occur in parts of southeast China. This type of event occurred in May 2015, causing serious flooding.

Introduction. The prerainy season in southern China usually starts in April with a rainbelt forming along the Indochina Peninsula. The rainbelt moves northward across eastern China throughout the rainy season, which generally lasts from May to August (Ding and Chan 2005). In 2015, the prerainy season began in early May, about a month later than normal. After the rainbelt was established, the rainfall was exceptionally heavy with the total precipitation in some southern provinces more than $50 \%$ greater than the 1971-2000 average (CMA 2016). The rain fell in a series of heavy storms, causing severe flooding in many cities with impacts that included loss of life.

We examine the change in the character of rainfall during May in terms of the number of consecutive days of rain, total rainfall over a period of $n$ days ( $n$ day totals), and rainfall intensity. Using these metrics, we estimate the regional change in probability of extreme precipitation due to anthropogenic climate forcing.

Data. We use model data from a pair of multidecadal ensemble experiments using the latest Met Office HadGEM3-A-based attribution system. Each ensemble comprises 15 members spanning the period 1960-2013, one set with both anthropogenic and natural forcings (ALL) and the other with natural only (NAT). The system is an upgrade to that used in a number of previous studies described by Christidis et al. (2013) to higher resolution (N216 L85, $0.56^{\circ} \mathrm{x}$ $0.83^{\circ}$ horizontally), the latest operational dynamical core (ENDGame; Wood and Stainforth 2010), and land surface model (JULES; Best et al. 2011), as well as an updated forcings set consistent with the CMIP5

AFFiliations: Burke, Stott, And Ciaverella-Met Office Hadley Centre, Exeter, United Kingdom; SuN-National Climate Center, China Meteorological Administration, Beijing, China DOI:I0.II75/BAMS-D-16-0I44.I

A supplement to this article is available online (10.1I75 /BAMS-D-16-0144.2) generation (Jones et al. 2011). Members differ from one another solely through the stochastic physics and share atmospheric initialization from ERA-40 at 0000 UTC 1 December 1959.

We use observed daily precipitation data for 19612015 provided by the Climate Data Center of China National Meteorological Information Center (NMIC). This dataset uses quality controlled data from 2419 stations and is the best daily dataset available for climate study in China. Yang and Li (2014) show that most of the daily precipitation series are homogeneous and lack pronounced discontinuities resulting from instrumental changes or station relocation.

Methods. We divide the flood-affected area of southeast China into 12 regions of $3^{\circ} \times 3^{\circ}$ areas with spatially coherent rainfall patterns and variability. Region locations and corresponding time series of total monthly rainfall for May are shown in Fig. 18.1. Monthly totals show no clear trends outside of interannual variability (see Supplemental Material for linear fits).There is also no clear separation of expected changes in monthly rainfall under anthropogenic and natural forcings. Given the large interannual variability of monthly totals and the nature of the floods in May 2015 being related to several large daily rainfall totals, we instead look at changes in intensity and duration of rainfall events.

For the month of May, we count the number of consecutive wet days (daily total rainfall $>=1 \mathrm{~mm}$ ) (n_days) and record the total rainfall during each $n$-day event (n_day_tot). We then calculate the mean intensity of rainfall in $\mathrm{mm} \mathrm{day}^{-1}$ for each event (intens). Using this metric, any given month can have several rainfall events.

For each $3^{\circ} \times 3^{\circ}$ region in southeast China, the mean of the observed station data and the mean of the grid cells for the model data are calculated for each day. This daily area-mean for each region is then used to calculate $n \_$days, $n_{-}$day_tot, and intens. We 
(a)

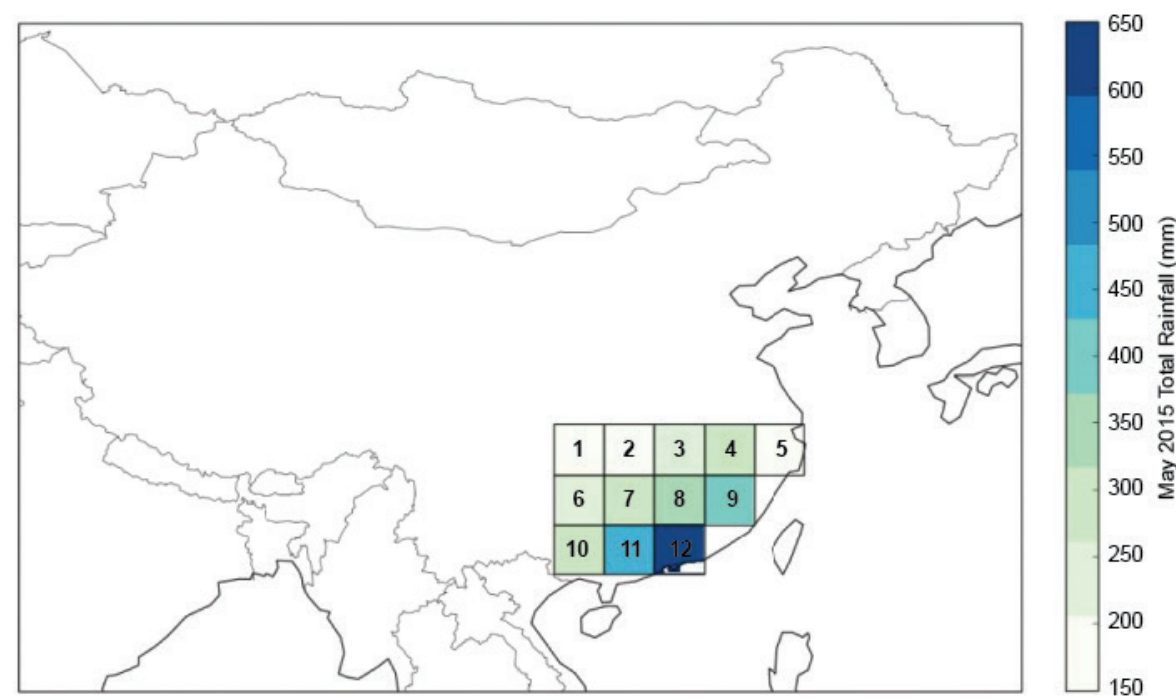

(b)

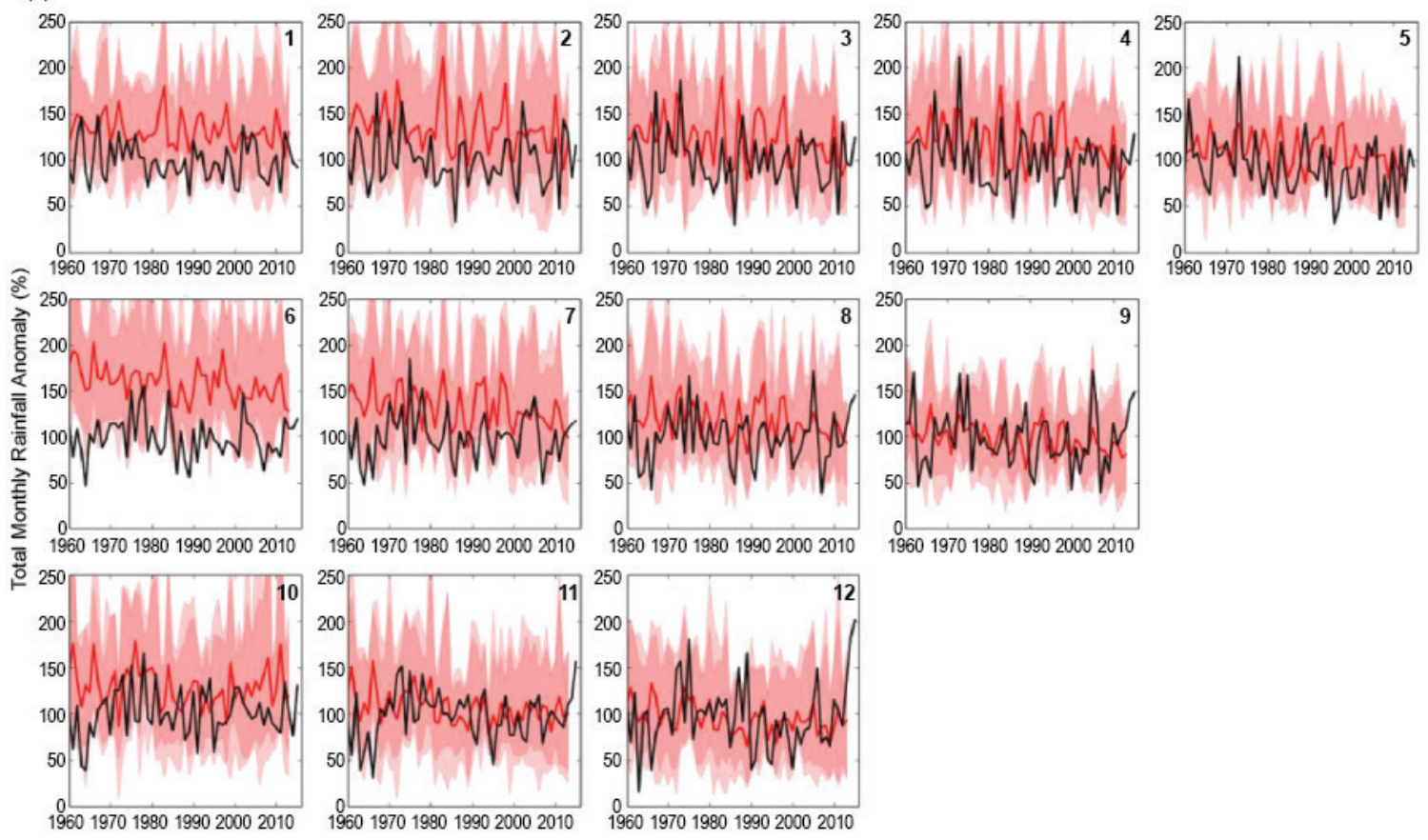

Fig. 18.I. (a) Regions of China examined in this study including total rainfall for May 2015. (b) Monthly total precipitation anomaly time series for regions I-12: observed totals (black lines), HadGEM3-A model mean (thick red lines), model ensemble 5th-95th percentile (dark red shading), and total model ensemble range (light red shading). Anomalies for both observations and models are with respect to 1961-90 climatology.

use all the available stations in each $3^{\circ} \times 3^{\circ}$ grid box, generally 40-60 stations, though the number of stations varies from year to year.

Model verification. We assess the capability of the models to represent daily rainfall characteristics and extremes by comparison of time series and rainfall intensity distributions between the model ensemble and the observations.
We plot observed and model time series total monthly rainfall for May, total number of rainy days, and maximum intens for each of 12 regions in Fig. 18.1 and Supplemental Fig. S18.1. The observed interannual variability of the time series clearly falls within the ensemble variability of HadGEM3-A, with the exception of region 6 , which we exclude from further analysis. Linear fits to the observed and modeled 
time series produce similar results albeit with low-fit significance (see Supplemental Material).

Supplemental Fig. S18.1 plots daily rainfall intensity distribution for the regions of southeast China. We perform a Kolmogrov-Smirnoff test (KS) for each region to determine how well the observed distribution of daily rainfall is reproduced by the ensemble mean - the results of this are indicated in the supplement. Nine of the 12 regions showed more than $95 \%$ likelihood of the observed and modeled distributions being drawn from the same population; an additional two regions showed $86 \%$. Region 10 showed only $72 \%$ likelihood and was excluded from further analysis.

The model can reproduce the mean and extremes of precipitation totals, intensities, number of rainy days in a month, and numbers of consecutive days of rain sufficiently well for the attribution study intended here.

Results. We select the top $10 \%$ of $n$ _day_tot rainfall to be defined as extreme events and examine the change in intens and $n_{-}$days over which this rain fell. The values for observed $n$ _days, $n$ _day_tot, and intens are shown in Supplemental Fig. S18.2 for all years including 2015. Following Christidis and Stott (2015), we take the most recent 15 years of model data (1999-2013) as representative of current climatology to produce probability distribution functions (PDF) for intens and $n_{-}$days. The PDF is calculated by fitting a gamma function to the normalized model histogram of the rainfall metric examined; we test the appropriateness of this fit in the supplement. PDFs allow the calculation of fraction of attributable risk (FAR; Allen 2003), defined as FAR $=1-(\mathrm{P}(\mathrm{NAT}) /$ $\mathrm{P}(\mathrm{ALL})$ ) for individual regions.

We calculate FAR for intensity of events greater than the May 2015 observed maximum, providing an estimate of the extent to which human influence has increased the risk of high-total-rainfall events with daily intensity as high as observed in May 2015. We also calculate FAR for the number of consecutive days of rain less than the maximum value observed for May 2015, providing an estimate of the extent to which human influence has increased the risk of having high-total-rainfall events with duration as short as in May 2015.

To calculate the error on FAR, we bootstrap resample (with replacement) the top $10 \%$ of $n_{\text {_d day_tot }}$ for the all-forcings and natural-forcings models then refit the PDFs 1000 times for both intens and $n$ _days. The standard deviation of the FAR from the 1000 bootstrapped samples gives the error on FAR.
We exclude regions 6 and 10 from analysis (see model verification) and report results for the remaining 10 regions. We find positive FAR in 4 out of 10 and 9 out of 10 regions for intens and $n$ _days, respectively. The four regions for which intens showed positive FAR-7, 8, 11, and 12-are all spatially adjacent to each other; these and all the coastal regions show positive FAR for $n$ _days. The spatial contiguity of regions with positive FAR makes it more likely that these results are physically caused rather than a statistical fluke.

Three regions show positive FAR at $2 \sigma$ in one metric and $1 \sigma$ in the other; we focus our analysis on those. We find positive FAR at $2 \sigma$ confidence for increase in intens and $1 \sigma$ confidence for decrease in $n$ _days in regions 7 and 12 . We find positive FAR at $2 \sigma$ confidence for decrease in $n_{-}$days and $1 \sigma$ confidence for increase in intens for region 11 . We also find positive FAR for regions 8 and 9 at $1 \sigma$ confidence for $n$ _days. We present results for regions 7,11 , and 12 in Fig. 18.2. For the top $10 \%$ of $n_{-}$day_tot, we find anthropogenic climate change has increased the likelihood of intense rainfall, greater than or equal to that observed in May 2015, by $64 \% \pm 17 \%, 23 \% \pm$ $12 \%$, and $66 \% \pm 19 \%$ for regions 7,11 , and 12 , respectively. For the same regions, we find anthropogenic influence increases likelihood by $12 \% \pm 11 \%, 39 \% \pm$ $14 \%$, and $23 \% \pm 14 \%$, respectively, of a decrease in the number of consecutive days over which the rain fell with respect to the maximum number of consecutive days observed in May 2015.

Some studies show that the Pacific sea surface temperature anomaly (SSTA) is an important factor affecting the early rainy-season precipitation in southern China (e.g., Qiang and Yang 2013). We tested for the effect of El Niño on our results and find no obvious correlation between ENSO-3.4 index and any of the three indices we examine from May 2015.

Conclusion. During May 2015, large daily rainfall totals were recorded over much of southeast China. While no clear trends are seen in the monthly total rain for this region, we find that the character of the rainfall has changed, such that the same total amount of rain falls in shorter more intense storms. We have shown that for the month of May, anthropogenically forced climate change has increased the probability of this kind of intense, short-duration rainfall (as occurred in 2015) for some regions of southeast China. In the future, we might expect more occurrences of short, intense rainfall events in these regions, increasing the likelihood of flooding. 
(a)

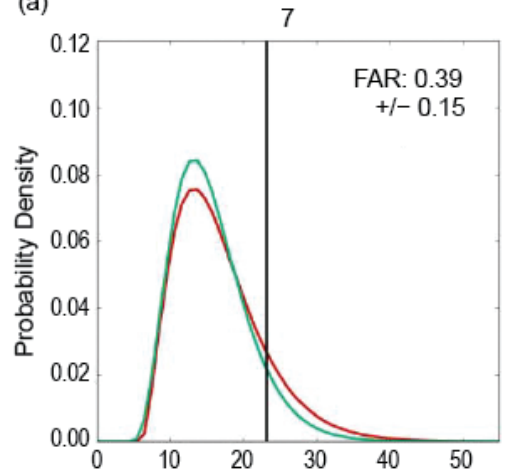

(b)

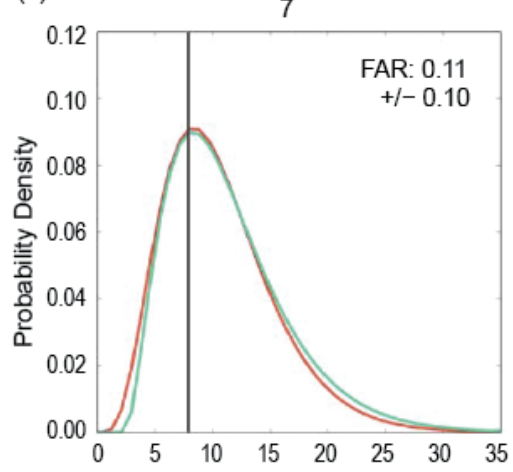

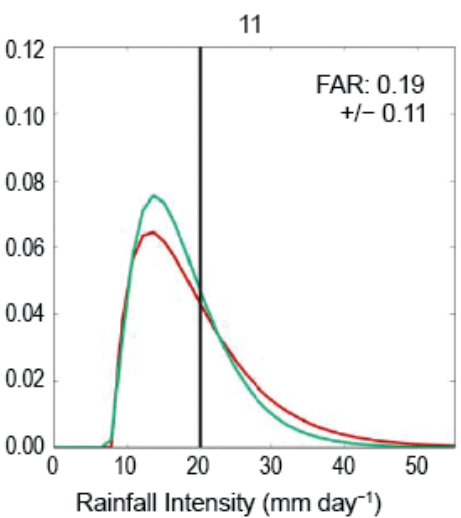
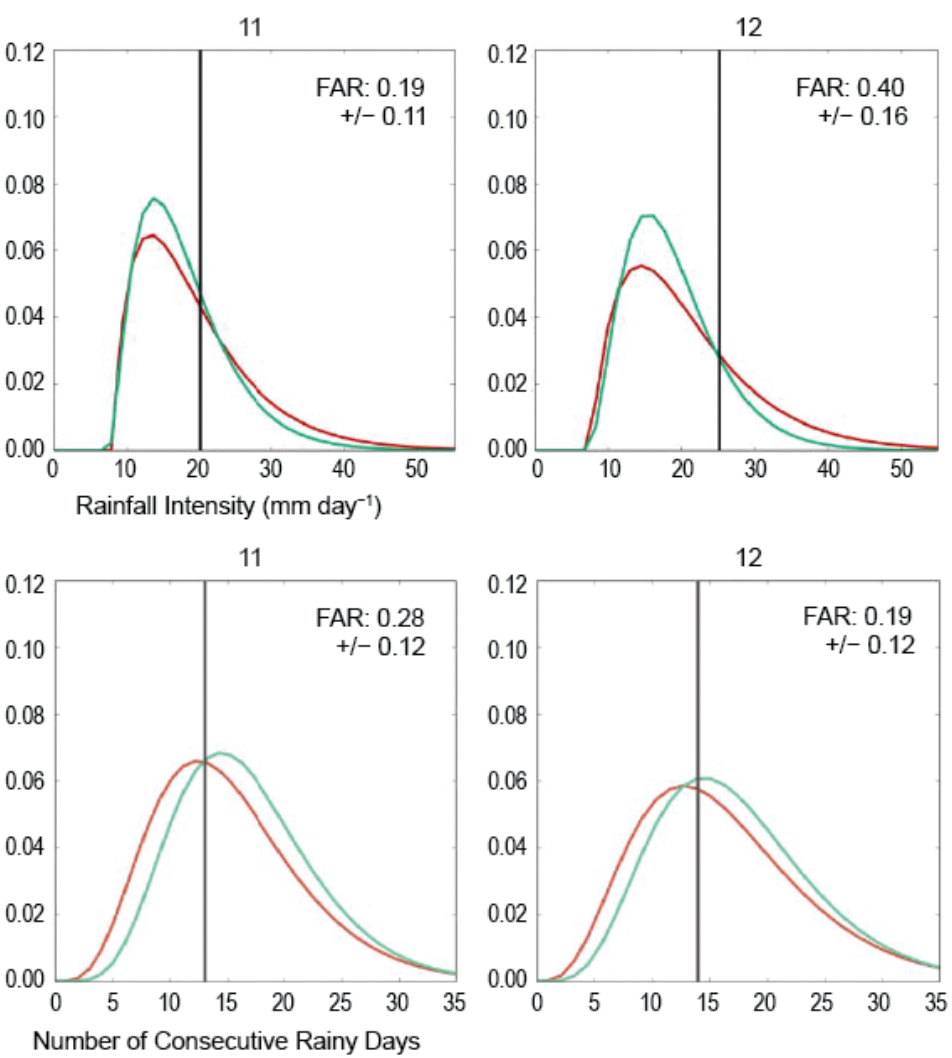

FIG. 18.2. (a) Probability distribution functions (PDFs) for the intensity of rainfall and (b) number of consecutive days of rain, where only the top $10 \%$ of rainfall total events (n_day_tot) defined by the observed 196I-90 climatology are selected. Red lines correspond to HadGEM3-A all forcings models (ALL); green is natural forcings only models (NAT); and black lines show the maximum value for May 20I5. FARs (FAR = I - (P(NAT) / P(ALL)) are indicated for each region. (a) FAR for intensity greater than the 2015 maximum value and (b) FAR for number of consecutive days of rain less than the 2015 maximum value. Only regions 7,11 , and 12 are shown.

ACKNOWLEDGEMENTS. This work and two of its contributors (Burke and Ciavarella) were supported by the UK-China Research and Innovation Partnership Fund through the Met Office Climate Science for Service Partnership (CSSP) China as part of the Newton Fund. This work was supported by the Joint DECC/Defra Met Office Hadley Centre Climate Programme (GA01101). Ying Sun is supported by China funding grants GYHY201406020 and 2012 CB417205.

\section{REFERENCES}

Allen, M., 2003: Liability for climate change. Nature, 421, 891-892, doi:10.1038/42189a.

Best, M. J., and Coauthors, 2011: The Joint UK Land Environment Simulator (JULES), model description - Part 1: Energy and water fluxes. Geosci. Model Dev., 4, 677-699, doi:10.5194/gmd-4-677-2011.

Christidis, N., P. A. Stott, A. A., Scaife, A. Arribas, G. S. Jones, D. Copset, J. R. Knight, and W. J. Tennant, 2013: A new HadGEM3-A-based system for attribution of weather-and climate-related extreme events. J. Climate, 26, 2756-2783, doi:10.1175 /JCLI-D-12-00169.1.

Christidis, N., and P. A. Stott, 2015: Extreme rainfall in the United Kingdom during winter 2013/14: The role of atmospheric circulation and climate change [in "Explaining Extreme Events of 2014 from a Climate Perspective"]. Bull. Amer. Meteor. Soc., 96 (12), S46S50, doi:10.1175/BAMS-D-15-00094.1. 
CMA, 2016: China Climate Bulletin 2015. China Meteorological Administration, 50 pp.

Davey, M. K., A. Brookshaw, and S. Ineson, 2014: The probability of the impact of ENSO on precipitation and near-surface temperature. Climate Risk Management, 1 (2014) 5-24, doi:10.1016/j.crm.2013.12.002.

Ding, Y. H., and J. C. L. Chan, 2005: The East Asian summer monsoon: An overview. Meteor. Atmos. Phys., 89, 117-142, doi:10.1007/s00703-005-0125-z.

Jones, C. D., and Coauthors, 2011: The HadGEM2-ES implementation of CMIP5 centennial simulations, Geosci. Model Dev., 4, 543-570, doi:10.5194/gmd-4 -543-2011.

Qiang, X. M., and X. Q. Yang, 2013: Relationship between the first rainy season precipitation anomaly in South China and the sea surface temperature anomaly in the Pacific (in Chinese). Chinese J. Geophys., 56 (8), 2583-2593.

Wood, L., and A. Stainforth., 2010: ENDGame Formulation v3. 01. Met Office paper.

Yang, S., and Q. Y. Li, 2014: Improvement in homogeneity analysis method and update of China precipitation data (in Chinese). Progressus Inquistitiones De Mutatione Climatis, 10 (4), 276 -281 . 


\section{Table 28.I. Summary of Results}

\section{ANTHROPOGENIC INFLUENCE ON EVENT}

\begin{tabular}{|c|c|c|c|}
\hline & INCREASE & DECREASE & NOT FOUND OR UNCERTAIN \\
\hline Heat & $\begin{array}{l}\text { Global Temperature (Ch. 2) } \\
\text { South India \& Sri Lanka (Ch. 2) } \\
\text { Central Europe (Ch. II) } \\
\text { Europe (Ch. I2) } \\
\text { Ethiopia and Southern Africa (Ch. I5) } \\
\text { N.W. China (Ch. I9) } \\
\text { W. China (Ch. 20) } \\
\text { Japan (Ch. 2I) } \\
\text { Indonesia (Ch. 22) } \\
\text { S. Australia (Ch. 23) } \\
\text { Australia (Ch. 24) }\end{array}$ & & Central Equitorial Pacific (Ch. 2) \\
\hline Cold & & Northeastern U.S. (Ch. 7) & $\begin{array}{l}\text { Mid-South Atlantic U.S. (Ch. 7) } \\
\text { N. America (Ch. 8) }\end{array}$ \\
\hline $\begin{array}{l}\text { Heat \& } \\
\text { Humidity }\end{array}$ & $\begin{array}{l}\text { Egypt (Ch. I4) } \\
\text { India \& Pakistan (Ch. 16) }\end{array}$ & & \\
\hline Dryness & $\begin{array}{l}\text { Indonesia (Ch. 22) } \\
\text { Tasmania (Ch. 25) }\end{array}$ & & \\
\hline $\begin{array}{l}\text { Heavy } \\
\text { Precipitation }\end{array}$ & China (Ch. 18) & & $\begin{array}{l}\text { Nigeria (Ch. I3) } \\
\text { India (Ch. I7) }\end{array}$ \\
\hline Sunshine & United Kingdom (Ch. I0) & & \\
\hline Drought & $\begin{array}{l}\text { Canada (Ch. 9) } \\
\text { Ethiopia and Southern Africa (Ch. I5) }\end{array}$ & & \\
\hline $\begin{array}{l}\text { Tropical } \\
\text { Cyclones }\end{array}$ & Western North Pacific (Ch. 26) & & \\
\hline Wildfires & Alaska (Ch. 4) & & \\
\hline $\begin{array}{l}\text { Sea Ice } \\
\text { Extent }\end{array}$ & & Arctic (Ch. 27) & \\
\hline $\begin{array}{l}\text { HIGH TIDE } \\
\text { FLOODS }\end{array}$ & SOUtheastern U.S. (CH. 6) & & \\
\hline $\begin{array}{l}\text { SNOWPACK } \\
\text { DROUGHT }\end{array}$ & WASHINGTON U.S. (CH. 5) & & \\
\hline TOTAL & 23 & 2 & 5 \\
\hline
\end{tabular}




\section{METHOD USED}

Heat

Ch. 2: CMIP5 modeling

Ch. II: Observations; weather@home modeling

Ch. 12: HadGEM3-A modeling

Ch. 15: CMIP5 modeling

Ch. 19: CMIP5 modeling with ROF; FAR

Ch. 20: CMIP5 modeling with ROF; FAR

Ch. 21: MIROC5-AGCM modeling

Ch. 22: Observations; CMIP5 modeling

Ch. 23: weather@home modeling; FAR

Ch. 24: BoM seasonal forecast attribution system and seasonal forecasts

Ch. 7: Observations; CMIP5 modeling

Ch. 8: AMIP (IFS model) modeling

Heat \&

Ch. 14: weather@home modeling

Humidity

Ch. 16: Non-stationary EV theory; C20C+ Attribution Subproject

Dryness

Ch. 22: Observations; CMIP5 modeling

Ch. 25: Observations; Modeling with CMIP5 and weather@home

Ch. 13: Observations; Modeling with CAM5.I and MIROC5

Heavy

Precipitation

Ch. 17: Observations; Modeling with weather@home, EC-Earth and CMIP5

Ch. 18: HadGEM3-A-N216 modeling; FAR

Sunshine

Ch. 10: Hadley Centre event attribution system built on the high-resolution version of HadGEM3-A

Ch. 9: Observations; CMIP5 modeling; Trend and FAR analyses

Drought

Ch. 15: CMIP5 modeling, land surface model simulations, and statistical analyses

Tropical

Cyclones

Ch. 26: GFDL FLOR modeling; FAR

Wildfires

Ch. 4: WRF-ARW optimized for Alaska with metric of fire risk (BUI) to calculate FAR

Sea Ice

Extent

HIGH TIDE

FLOODS

SNOWPACK

DROUGHT

Ch. 27: OGCM modeling

CH. 6: Tide-gauge data; Time-dependent EV statistical model

Ch. 5: Observations; CESMI modeling

\section{ACRONYMS:}

AMIP: Atmospheric Model Intercomparison Project

BoM: Bureau of Meteorology, Australia

BUI: Buildup Index

CAM: Community Atmosphere Model, http:www.cesm.ucar.edu

CESM: Community Earth System Model

CMIP: Coupled Model Intercomparison Project

FAR: Fraction of Attributable Risk

EC-EARTH: https://verc.enes.org/

EV: Extreme Value
GFDL FLOR: Geophysical Fluid Dynamics Laboratory Forecast version Low Ocean Resolution

GHCN: Global Historical Climatology Network

IFS: Integrated Forecast System

MIROC5-AGCM: Model for Interdisciplinary Research on ClimateAtmospheric General Circulation Model

OGCM: Ocean General Circulation Model

ROF: Regularized Optimal Fingerprinting

weather@home: http:www.climateprediction.net/weatherathome

WRF-ARW: Advanced Research (ARW) version of the Weather Research and Forecasting (WRF) model 